\title{
La libertad de expresión en Argentina y su comparación con la jurisprudencia de la Corte Interamericana: parecidos y diferencias entre los casos "Patitó" y "Kimel"
}

Este comentario, junto a los documentos que analiza, está disponible en www.anuariocdh.uchile.cl

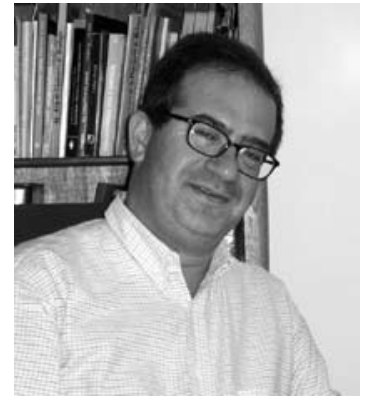

\section{Hernán Gullco}

Abogado, Master of Laws in Comparative Law, University of Miami, profesor de Clínica Jurídica de la Universidad Torcuato Di Tella, ciudad autónoma de Buenos Aires, Republica Argentina, y Director del Área de Litigios de la Asociación por los Derechos Civiles (ADC).

hgullco@utdt.edu

\section{RESUMEN}

El presente comentario analiza, por una parte, los aspectos más relevantes de la sentencia de la Corte Suprema argentina en el caso Patitó, José Angel y otro c. Diario La Nación, del 24 junio de 2008. Por otra, se examinan los parecidos y diferencias entre ese pronunciamiento y los principios elaborados por la Corte Interamericana en el Caso Kimel v. Argentina. Finalmente, se formula una crítica a la negativa de la Corte Suprema argentina de aplicar al caso Patitó la jurisprudencia de la Corte Interamericana respecto de la distinción entre hechos y juicios de valor, en atención a la importancia de esta diferenciación para una correcta comprensión de los alcances del derecho a la libre expresión.

\section{Introducción}

El día 24 de junio de 2008, la Corte Suprema argentina dictó en la causa Patitó, José Angel y otro c. Diario La Nación y otros una sentencia que desarrolla principios muy importantes acerca del alcance del derecho a la libertad de expresión.

En el presente trabajo intentaré señalar cuáles son los aspectos más relevantes de la decisión de la Corte Suprema, además de los parecidos y diferencias entre ésta y los principios elaborados por la Corte Interamericana respecto de la misma cuestión en su reciente decisión en el caso Kimel v. Argentina ${ }^{1}$. Asimismo, trataré de demostrar que la negativa de la mayoría de la Corte Suprema de aplicar al caso la jurisprudencia de la distinción entre hechos y juicios de valor de la Corte Interamericana, es cuestionable porque introduce ciertas confusiones acerca del alcance del derecho a la libre expresión ${ }^{2}$.

1 Corte IDH. Caso Kimel Vs. Argentina. Fondo, Reparaciones y Costas. Sentencia de 2 de mayo de 2008 Serie C No 177. Disponible en http://www.corteidh.or.cr/pais.cfm?id_Pais=2

2 En el presente comentario no se examinará la aplicación al caso de la doctrina del caso Campillay (Fallos: 308:789) de la Corte argentina, materia que fue tratada en los votos concurrentes de los jueces Highton de Nolasco y Maqueda. Conforme con esta doctrina, bajo ciertas circunstancias el informador no es responsable si transcribe el contenido de una fuente producida por un tercero. 


\section{Antecedentes del caso}

Los hechos del caso Patitó aparecen descritos en el considerando $1^{\circ}$ del voto de la mayoría de la Corte Suprema ${ }^{3}$ :

"[...] [L]os actores, integrantes del Cuerpo Médico Forense del Poder Judicial de la Nación (en adelante CMF.), promovieron demanda contra el diario La Nación y contra el periodista J. U. B., con el objeto de que se los condenara a resarcir los daños que les habrían provocado las notas de fechas 1 y 13/12/1997, 30/1/1998, 13/3/1998, 1 y 15/4/1998, 14/10/1998, 11/11/1998, 24/2/1999, 1/3/1999, 14/3/1999, 13 y 14/4/1999, 15/6/1999, 11/8/1999 y el editorial del 19/10/1998. Adujeron que los demandados, mediante las noticias, sus títulos y subtítulos y el editorial, cuestionaron su desempeño profesional como integrantes del referido CMF, con especial referencia a dos causas penales relacionadas con el fallecimiento de la Sra. C. B. A. y su hijo por nacer en la maternidad Sardá. De tal manera -precisaron los actores- el diario y el periodista afectaron los derechos constitucionales a la intimidad y al honor, en tanto las publicaciones fueron inexactas, formaron parte de una campaña persecutoria y difamatoria contra ellos y, en lugar de informar, tomaron una abierta posición sobre el tema, con la intención de despertar en el público sospechas sobre su actuación profesional".

La sala $\mathrm{H}$, de la Cámara Nacional de Apelaciones en lo Civil de la Ciudad de Buenos Aires, al confirmar el 17 de junio de $2004^{4}$ la sentencia de $1^{\mathrm{a}}$ instancia, acogió la demanda promovida contra el diario La Nación, pero la rechazó respecto del periodista del diario. Para fundar esa condena, la Cámara tuvo especialmente en cuenta la opinión editorial del diario del 19 de octubre de 1998, que se transcribe parcialmente a continuación:

"Transparencia de peritajes forenses. Como si la credibilidad del sistema judicial no estuviera ya bastante depreciada, el escándalo que ahora ha estallado en torno del cuerpo médico forense de la Corte Suprema ha venido a ahondar el escepticismo que se ha generalizado en la sociedad argentina respecto de la calidad del servicio de justicia que presta el Estado, y a agudizar las suspicacias sobre comportamientos criminales en esferas vinculadas con el poder político [...]

Los médicos forenses, como otros profesionales en sus respectivas especialidades, son auxiliares imprescindibles de la Justicia. Sobre la base de sus dictámenes reposa una gran parte de la eficacia de los procedimientos jurídicos, y los magistrados no pueden prescindir, en la generalidad de los casos, de su opinión debidamente fundada en consideraciones científicas objetivas: un pronunciamiento pericial suele tener el carácter de un verdadero prenuncio de las decisiones del juez, sea en cuestiones de fondo o incidentales.

Pero por esa misma razón los cuerpos de peritos deben ser absolutamente confiables. El fuerte deterioro moral que conllevan dictámenes falaces o amañados, producto de presiones inducidas desde posiciones política o económicamente influyentes, o peritajes negligentes realizados irresponsablemente con desconocimiento u olvido de su crucial trascendencia para el desarrollo de un proceso daña las bases mismas del sistema judicial al poner en manos del magistrado elementos de juicio que distorsionan la realidad.

En este caso, para peor, aparece una cierta forma de estructura ilegal en el ámbito forense que intenta disimular o encubrir con criterio corporativo un encadenamiento de hechos irregulares

3 La sentencia de la mayoría fue suscrita por los jueces Lorenzetti, Fayt Argibay y Zaffaroni. Por su parte, los jueces Highton de Nolasco, Maqueda y Petracchia emitieron sendos votos concurrentes. En este comentario, me concentraré especialmente en analizar el voto de la mayoría y el voto concurrente del juez Petracchia. El fallo se encuentra disponible en http://www.csjn.gov.ar/documentos/cfal3/cons_fallos.jsp

4 El fallo de la Cámara de Apelaciones se encuentra publicado en www.elDial.com AA21BA. 
perpetrados por profesionales médicos que ha llevado al juez a requerir peritajes fuera del ámbito del Cuerpo Médico Forense de la Corte Suprema, bajo la sospecha de que sus procedimientos son incorrectos y sus dictámenes falsean la verdad. El resultado de tales peritajes viene a avalar las sospechas, calificando como incoherente, temerario, negligente y no confiable -entre otros términos convergentes- el trabajo de los peritos de la Corte.

En vista de estos hechos, el Máximo Tribunal de la Nación ha dispuesto una auditoría en el Cuerpo Médico Forense y el juez Mariano Bergés citó a prestar declaración indagatoria a tres decenas de forenses sospechados del intento de encubrir con su dictamen los errores e irregularidades de otros colegas. Es menester, para que el prestigio de la Justicia no siga mermando, que la investigación llegue a conclusiones indubitadas y el cuerpo de peritos resulte depurado -si es necesario- para recuperar la imprescindible credibilidad.

Es cierto que el sistema judicial argentino padece muchas otras deficiencias que son notorias, en todos los niveles de la administración de Justicia, pero la falta de un cuerpo médico forense responsable, en cuyo cabal sentido de su función profesional se pueda confiar, es una carencia insalvable cuando se trata de llegar a la verdad sobre hechos que golpean duramente la sensibilidad de la gente y suelen adquirir incluso gravitación política".

En su sentencia, la Cámara de Apelaciones había sostenido, en primer lugar, que no resultaba aplicable al caso la doctrina de la "real malicia", elaborada por la Corte Suprema estadounidense en el caso New York Times v. Sullivan (376 U.S. 254) y que había sido adoptada por la Corte argentina ${ }^{5}$. Se indicó que esta doctrina sólo servía para juzgar las expresiones que consistían juicios de hechos y no, como en el caso, en opiniones o valoraciones.

Igualmente, al establecer la responsabilidad del diario la Cámara sostuvo: "el desacierto [del medio de prensa demandado] se evidenció en volcar un juicio de valor apresurado e inoportuno en un momento en que la justicia investigaba un hecho y el magistrado aún no se había pronunciado, ya que precisamente la investigación judicial procuraba desentrañar si el cuerpo de médicos había procedido del modo en que el periódico afirmó" (Punto VI del voto del juez Kiper que contó con la adhesión de sus colegas).

Esta decisión fue apelada por el diario "La Nación" ante la Corte Suprema.

\section{La decisión de la Corte Suprema}

En el voto de la mayoría de la Corte Suprema se recordó, en primer lugar, la importancia central que la tradicional jurisprudencia de ese tribunal había otorgado a la libertad de expresión como aspecto central para la subsistencia del sistema democrático (considerando $5^{\circ}$ ).

A continuación, el tribunal hizo referencia a la tradicional distinción hecha en la jurisprudencia del Tribunal Europeo de Derechos Humanos entre "hechos" y "juicios de valor":

"Sin embargo, para la Corte argentina la citada distinción tenía [...] sentido en tren de explicar por qué un ordenamiento jurídico que recurre a la prueba de la verdad, como criterio para discernir responsabilidad civil o penal por difamación, no protege suficientemente la libertad de expresión.

5 En el considerando $8^{\circ}$ de su decisión en el caso Patitó, la Corte Suprema reseñó la doctrina de la "real malicia", tal como aquélla había sido receptada en su jurisprudencia: "[...] según los precedentes de esta Corte, tratándose de informaciones referidas a funcionarios públicos, figuras públicas o particulares que hubieran intervenido en cuestiones de esa índole, cuando la noticia tuviera expresiones falsas o inexactas, los que se consideran afectados deben demostrar que quien emitió la expresión o imputación conocía la falsedad de la noticia y obró con conocimiento de que eran falsas o con notoria despreocupación por su veracidad (doctrina de Fallos 320:1272; 327:943)". 
Es lo que hizo el tribunal mencionado en el caso 'Lingens', fallado el 8/7/1986, en cuyo apart. 46 se encuentra esa frase, pero no solamente ella. Según se explica en la sentencia, el derecho austríaco establecía que si las expresiones eran objetivamente aptas para difamar, los periodistas sólo tenían posibilidad de evitar la condena cuando podían 'probar la veracidad de sus afirmaciones'. Inmediatamente después el tribunal europeo concluyó que una prueba semejante no podía 'cumplirse respecto de juicios de valor y afecta a la libertad de opinión intrínsecamente'.

Por lo tanto, el señalamiento sobre la importancia de 'distinguir entre hechos y juicios de valor' fue utilizado por el Tribunal Europeo para ampliar la protección de la libertad de expresión más allá de las afirmaciones de hecho y alcanzar con ella a las opiniones o evaluaciones.

De todos modos, no es la prueba de la verdad el tipo de protección que este tribunal ha reconocido a la libertad de expresión al adoptar el test conocido como de la 'real malicia', tomándolo del precedente 'New York Times v. Sullivan'” (voto cit., considerando $7^{\circ}$ ).

En el considerado siguiente de su sentencia, la Corte Suprema recordó los principios centrales de la doctrina de la "real malicia" 6 y sostuvo que aquéllos:

"[...] eran consistentes con el diseño de un estado de derecho constitucionalmente reglado. La investigación periodística sobre los asuntos públicos desempeña un rol importante en la transparencia que exige un sistema republicano. El excesivo rigor y la intolerancia del error llevarían a la autocensura, lo que privaría a la ciudadanía de información imprescindible para tomar decisiones sobre sus representantes.

Estas afirmaciones forman parte del acervo común de los jueces de importantes tribunales que han adoptado una línea de interpretación amplia, admitiendo incluso el error sobre los hechos. En este sentido, la Corte Suprema de Estados Unidos consideró que '[l]as afirmaciones erróneas son inevitables en un debate libre, y éste debe ser protegido si la libertad de expresión ha de tener el espacio que ella necesita para sobrevivir' ('New York Times v. Sullivan', 376 U.S. 254, 271). Por su parte, el Tribunal Constitucional español sostuvo, en su sent. 6/1988, que '[...] [l]as afirmaciones erróneas son inevitables en un debate libre, de tal forma que de imponerse 'la verdad como condición para el reconocimiento del derecho [de expresarse libremente], la única garantía de la seguridad jurídica sería el silencio [...]' (Jurisprudencia Constitucional, t. XX, p. 57)".

La Corte argentina sostuvo, con base en estas consideraciones, que no era necesario "[...] crear otro estándar para juzgar las difamaciones ocasionadas mediante puras opiniones. Una conclusión semejante debe ser prevenida recordando que en el marco del debate público sobre temas de interés general, y en especial sobre el gobierno, toda expresión que admita ser clasificada como una opinión, por sí sola, no da lugar a responsabilidad civil o penal a favor de las personas que ocupan cargos en el Estado; no se daña la reputación de éstas mediante opiniones o evaluaciones, sino exclusivamente a través de la difusión maliciosa de información falsa. Por lo demás, no se trata el presente caso de otras posibles afectaciones de lo que genéricamente se denomina honor, distintas de la difamación, tales como las expresiones ofensivas, provocativas o irritantes, que pueden caber en la categoría de 'insulto' (Fallos 321:2558, voto de los jueces Petracchia y Bossert)" (considerando cit.).

La aplicación de estos principios al caso llevó a la mayoría de la Corte Suprema a sostener y concluir que:

6 Ver Nota 5. 
"[...] en la causa los actores no han aportado elementos que permitan concluir que el diario conocía la invocada falsedad de los hechos afirmados en el editorial o que obró con notoria despreocupación acerca de su verdad o falsedad [...] (considerando 11).

[...] [E]n suma, puede afirmarse que el texto examinado del editorial publicado el 19/10/1998, no es apto para generar la responsabilidad del diario demandado. En consecuencia, la decisión apelada que responsabilizó al referido diario, constituye una restricción indebida a la libertad de expresión, por lo que debe ser revocada" (considerando 12).

\section{Semejanzas y diferencias entre el fallo Patitó y la jurisprudencia de la Corte Interamericana}

Resulta evidente que algunos de los argumentos utilizados en este caso por la Corte argentina $^{7}$ son muy similares a los empleados por la Corte Interamericana de Derechos Humanos en su jurisprudencia sobre el alcance del artículo 13 de la Convención Americana ${ }^{8}$.

Por ejemplo, el fuerte énfasis puesto por la Corte argentina en la importancia del derecho a la libertad de expresión para la subsistencia del sistema democrático, ha sido parte desde sus inicios de la jurisprudencia de la Corte Interamericana9 ${ }^{9}$

También son similares las consideraciones efectuadas por la Corte Suprema respecto de la necesidad de extremar la protección de la libre expresión en temas de interés público que involucren la actuación de funcionarios públicos en el ejercicio de sus actividades específicas ${ }^{10}$.

Sin embargo, la sentencia en el caso Patitó no coincide con la jurisprudencia de la Corte Interamericana en lo relativo a la relevancia que este último tribunal asigna a la distinción entre "hechos" y "opiniones". En el caso "Kimel", la Corte Interamericana hizo hincapié en tal distinción indicando que:

“92. La Corte observa que el señor Kimel realizó una reconstrucción de la investigación judicial de la masacre y, a partir de ello, emitió un juicio de valor crítico sobre el desempeño del Poder Judicial durante la última dictadura militar en Argentina [...]

93. Las opiniones vertidas por el señor Kimel no pueden considerarse ni verdaderas ni falsas. Como tal, la opinión no puede ser objeto de sanción, más aún cuando se trata de un juicio de valor sobre un acto oficial de un funcionario público en el desempeño de su cargo. En principio, la verdad o falsedad se predica sólo respecto a hechos. De allí que no puede ser sometida a requisitos de veracidad la prueba respecto de juicios de valor"11.

Fue, precisamente, la característica de "juicio de valor" de las manifestaciones del denunciante el elemento decisivo en la determinación por parte de la Corte Interamericana de una violación de su derecho a la libre expresión. A juicio de la Corte los dichos del denunciante constituían "[...]

7 En este punto, a los fines de sintetizar los argumentos de la Corte argentina, me remito a la reseña que efectué en el punto anterior de este comentario.

8 Por otra parte, en el considerando 13 del voto concurrente de la jueza Highton de Nolasco se hizo una referencia específica a la decisión de la Corte Interamericana en el caso Herrera Ulloa Vs. Costa Rica. Excepciones Preliminares, Fondo, Reparaciones y Costas. Sentencia de 2 de julio de 2004. Serie C No 107.

9 Corte IDH. Caso Kime/ Vs. Argentina. Párr. 57 y su cita.

10 Ibíd. Párrs. 86 y 87.

11 Énfasis añadido. 
una opinión que no tenía relación con la vida personal del Juez querellante ni le imputaba una conducta ilícita, sino que se relacionaba con la causa judicial a su cargo"12.

\section{El error incurrido por la Corte argentina: la importancia práctica de distinguir entre hechos y opiniones}

La primera crítica que puede formularse a los fundamentos empleados por la mayoría de la Corte argentina consiste en que el citado tribunal no tuvo en cuenta la distinción efectuada en "Kimel" por la Corte Interamericana entre "hechos" y "opiniones", a pesar de que la decisión de esta última había sido emitida antes de la sentencia del caso Patitó. Ello no parece recomendable si se tiene en cuenta que, como la propia Corte argentina lo ha señalado ${ }^{13}$, la jurisprudencia de la Corte Interamericana posee valor paradigmático para la labor de interpretación de la Convención Americana de los jueces de los Estados parte de este tratado ${ }^{14}$.

En segundo lugar, es evidente la gran importancia que posee distinguir entre "hechos" y "opiniones", por diversos motivos.

Es incorrecta la afirmación del voto de mayoría en el caso Patitó de que "[...] no es la prueba de la verdad el tipo de protección que este tribunal ha reconocido a la libertad de expresión al adoptar el test conocido como de la 'real malicia', tomándolo del precedente 'New York Times v. Sullivan'”. Para la doctrina de la "real malicia" la determinación de si una afirmación es verdadera o falsa es decisiva para fines de determinar si aquella merece protección constitucional, pues conforme con ella, las afirmaciones falsas no merecen, en principio, dicha defensa. La doctrina de la "real malicia" busca prevenir el peligro de autocensura limitando el alcance de responsabilidad por la difusión de informaciones inexactas al exigir, en ciertos casos, la prueba de un elemento subjetivo especial por parte del informador como requisito para fundar la responsabilidad de aquél ${ }^{15}$.

Como contrapartida natural de esta doctrina, la difusión de informaciones veraces en temas de interés público no debería dar lugar a la responsabilidad del informador, más allá de las molestias que dicha información pudiera causar a terceros.

Ello fue claramente señalado por la Corte Suprema estadounidense en el caso Bartnicki v. Vopper (532 U.S. 514), al reseñar su tradicional jurisprudencia sobre la cuestión:

"[c]omo principio general, 'la acción estatal de sancionar la publicación de información veraz, rara vez puede satisfacer las exigencias constitucionales' [...] Más específicamente, esta Corte ha señalado repetidamente que 'si un periódico obtiene legítimamente información veraz sobre un tema de relevancia pública, entonces los funcionarios estatales no están facultados constitucionalmente a sancionar la publicación de la información, si no existe una necesidad de orden superior' [...]".

Un criterio similar fue seguido por el Tribunal Europeo de Derechos en el caso Schwabe v. Austria (A 242-B; sentencia del 28.8.92) ${ }^{16}$. En este caso el tribunal resolvió que la difusión pública por parte del denunciante de antiguos antecedentes judiciales de un político -en el caso, la condena

12 Corte IDH. Caso Kimel Vs. Argentina. Párr. 91.

13 Mazzeo; sentencia del 13.7.2007, publicada en J.A. 2007-III-573.

14 En este punto, la Corte argentina citó la decisión de la Corte Interamericana en el caso Almonacid Arellano Vs. Chile. Excepciones Preliminares, Fondo, Reparaciones y Costas. Sentencia de 26 de septiembre de 2006. Serie C No 154, párr. 124.

15 Ver, en tal sentido, la nota 5 de este comentario y la decisión de la Corte Suprema estadounidense en el caso Gertz v. Robert Welch, 418 U.S. 323, en donde se ratificó y precisó la doctrina del caso New York Times v. Sullivan.

16 Este fallo está disponible en :http://cmiskp.echr.coe.int/tkp197/view.asp?item=1\&portal=hbkm\&action=html\&highlight $=$ schwabe $\% 20 \% 7 \mathrm{C} \% 20$ austria $\&$ sessionid $=15386406 \&$ skin=hudoc-en 
de homicidio por imprudencia bajo la influencia del alcohol- se encontraba protegida por el derecho a la libertad de expresión, pues tales datos podían ser factores relevantes al momento de determinar la idoneidad del funcionario para ejercer funciones políticas (párr. 32).

Sin embargo, también es claro que, en otros supuestos, la "verdad" o "falsedad" de una afirmación no son relevantes y que, en consecuencia, es necesario recurrir a un estándar diferente para determinar la legitimidad de la restricción a la libre expresión. Un ejemplo de ello lo encontramos ante informaciones verdaderas que son consideradas violatorias del derecho a la intimidad.

Así, en el caso Carolina von Hannover v. Alemania (sentencia del 24.6.2004) ${ }^{17}$, el Tribunal Europeo decidió que constituía una interferencia injustificada en el derecho a la intimidad de la denunciante (artículo 8 de la Convención Europea de Derechos Humanos) ${ }^{18}$ la publicación de fotos de aquélla que la mostraban, por ejemplo, en un restaurante con otra persona. El Tribunal señaló que, en ciertos supuestos, el derecho del público a la información "[...] podía incluso extenderse a aspectos de la vida privada de las personas que actúan en la vida pública, especialmente cuando se trata de políticos [...] [pero] ello no ocurrió en el presente caso. La situación aquí no cae dentro de la esfera de ningún debate político o público, dado que las fotos publicadas y el texto que las acompañan se refieren exclusivamente a detalles de la vida privada de la denunciante [...] Como ha ocurrido en casos similares en que ha tenido que resolver, el Tribunal considera así que en el presente caso la difusión de las fotos y del artículo cuestionados quería sólo satisfacer la curiosidad de un público determinado sobre la vida privada de la denunciante $y$, a pesar del alto grado de conocimiento que existe respecto de esta última, dicha publicación no puede ser vista como una contribución a discusión alguna de interés público para la sociedad [...]" (párrs. 64/65).

Tampoco son relevantes las consideraciones acerca de la verdad o falsedad cuando nos encontramos ante juicios de valor considerados denigrantes. Así, el Tribunal Constitucional de la República Federal Alemana (BVerfCe 86,1; sentencia del 25.3.1992) ${ }^{19}$ resolvió que no se encontraba protegido por el derecho a la libertad artística reconocido en la Ley Fundamental de ese país el calificativo de "tullido" respecto de una persona que padecía de una severa discapacidad física.

\section{Conclusión}

La solución a la que arribó la Corte Suprema argentina en el caso Patitó debe ser celebrada porque constituye una fuerte defensa del derecho de los medios de prensa a formular comentarios críticos respecto de la actividad oficial de funcionarios públicos.

Sin embargo, la negativa de la mayoría del tribunal en aceptar la tradicional distinción entre "hechos" y "opiniones" ${ }^{20}$ es cuestionable.

En efecto, a pesar de la innegable dificultad que existe en muchos casos para trazar una línea divisoria entre ambos conceptos ${ }^{21}$ esa diferenciación, tal como hemos visto, es una herramienta muy útil para distinguir los diversos supuestos de restricciones a la libre expresión, los cuales no pueden ser resueltos con un estándar único. Contrariamente a lo que se infiere del voto mayoritario en el

17 Disponible en http://cmiskp.echr.coe.int/tkp197/view.asp?item=1\&portal=hbkm\&action=html\&highlight=von $\% 20$ $\% 7$ \%20hannover\&sessionid=15386406\&skin=hudoc-en

18 Redactado en términos similares a los del artículo 11 de la Convención Americana.

19 Este fallo se encuentra disponible en http://www.servat.unibe.ch/dfr/bv086001.html

20 En cambio, en los votos concurrentes emitidos en el caso sí se aceptó la mencionada distinción.

21 Ver, en tal sentido, el comentario IBARLUCIA, E. Nuevas precisiones sobre las reglas de las doctrinas "Campillay" y de la real malicia. Revista La Ley. 30 de octubre de 2008. El autor reseña la opinión del Procurador General en el caso "Patitó" quien se muestra escéptico de la posibilidad de efectuar tal distinción. 
caso Patitó, al examinar el caso "Lingens" la distinción entre "hechos" y "opiniones" no se fundó exclusivamente en la necesidad de cuestionar la exigencia de la prueba de la verdad contenida en el derecho austriaco. Antes bien, la adopción de tal criterio de distinción parece estar basado en el hecho evidente de que en muchos casos la cuestión central a resolver por los tribunales es si la información es verdadera o falsa ${ }^{22}$ y, en cambio, en otros casos tal averiguación no es decisiva a los fines de determinar si corresponde imputar responsabilidad. En este último supuesto, el tema central a resolver será si el informador violó el derecho de terceros de verse libres de injerencias arbitrarias en su vida privada o de no verse sometido a juicios de valor humillantes.

Es por ello que me parece que resulta mucho más adecuada la afirmación contenida en el voto concurrente del juez Petracchia ${ }^{23}$ de que "[...] el estándar de la real malicia 'resulta inaplicable a los supuestos de expresión de ideas, opiniones y juicios de valor. En otras palabras, sólo cuando se trata de la afirmación de hechos es posible sostener un deber de veracidad como el que subyace al estándar de 'New York Times v. Sullivan'. Ello es así, pues respecto de las ideas, opiniones, juicios de valor, juicios hipotéticos o conjeturales [...] no es posible predicar verdad o falsedad' [...]" (voto cit., considerando $5^{\circ}$ ).

Igualmente, parece preferible la conclusión a la que arribó el nombrado juez, fundado en dicha premisa, de que sólo correspondía:

“[...] tomar como objeto de posible reproche jurídico la utilización de palabras inadecuadas, esto es, la forma de la expresión y no su contenido pues éste, considerado en sí, en cuanto de opinión se trate, es absolutamente libre [...]

Destaqué [en el mencionado caso "Amarilla"] que no era suficiente la indagación de los significados literales de los términos usados, pues resultaba necesario considerar 'la terminología usual en el contexto en el que han sido vertidos' y concluí señalando que 'el criterio de ponderación deberá estar dado, pues, por la ausencia de expresiones estricta e indudablemente injuriantes y que manifiestamente carezcan de relación con las ideas u opiniones que se expongan. En otras palabras, no hay un derecho al insulto, a la vejación gratuita o injustificada' (cit.).

6.- Que, en consecuencia, por aplicación del criterio de ponderación citado precedentemente, se concluye fácilmente en que nada hay en el texto del 19/10/1998 publicado en 'La Nación', que pueda ser considerado inútilmente vejatorio o insultante o que haya traspasado los límites anteriormente indicados. Que ese editorial haya molestado a los actores, se entiende, pero ello no constituye sino uno de los precios que hay que pagar por vivir en un [E]stado que respeta la libertad de expresión".

Por lo expuesto, considero que sería recomendable que en futuro la Corte argentina revise este aspecto del caso Patitó para así adoptar el criterio alternativo adoptado en el voto concurrente del juez Petracchi y que se ajusta a las pautas dominantes en la jurisprudencia de la Corte Interamericana y del Tribunal Europeo ${ }^{24}$.

22 Y, en caso afirmativo, qué grado de conocimiento tenía el informador acerca de dicha falsedad (conf. caso "New York Times v. Sullivan", cit.).

23 En este punto, el juez Petracchia se fundó en su opinión anterior en el caso Amarilla (Fallos: 321:2558).

24 Para un ejemplo reciente de la distinción entre hechos y opiniones en la jurisprudencia del T.E.DH., ver el caso Lombardo v. Malta, sentencia del 24.4.2007, párr. 58. Disponible en http://cmiskp.echr.coe.int/tkp197/view.asp?item=1\&portal= hbkm\&action=html\&highlight=lombardo $\% 20 \% 7 C \% 20$ malta\&sessionid=15386406\&skin=hudoc-en 